\title{
Supraorbital eyebrow keyhole approach for microsurgical management of ruptured anterior communicating artery aneurysm
}

\author{
ROBIN BHATTARAI, CHAOFENG LIANG, CHUAN CHEN, HUI WANG, \\ TENGCHAO HUANG, XINJIE NING and YING GUO
}

Department of Neurosurgery, Third Affiliated Hospital of Sun Yat-Sen University, Guangzhou, Guangdong 510630, P.R. China

Received June 26, 2019; Accepted December 13, 2019

DOI: $10.3892 /$ etm.2020.8909

\begin{abstract}
The mortality and disability rate of patients with ruptured anterior communicating artery (AComA) aneurysm after bleeding is high. Even with the most advanced treatment methods, the incidence of complications remains high. The purpose of the present study was to determine the efficacy of microsurgery via supraorbital eyebrow keyhole approach (SOEK) in clipping ruptured AComA aneurysms. Between September 2010 and October 2018,543 patients with intracranial aneurysms were admitted to the Department of Neurosurgery of the Third Affiliated Hospital of Sun Yat-Sen University (Guangzhou, China). Among them, 85 patients with ruptured AComA aneurysm and subarachnoid hemorrhage (SAH) underwent microsurgical clipping via the SOEK approach. In those patients, the clipping rate, complications and clinical efficacy of treatment were evaluated. The average age of the patients was $52.69 \pm 9.94$ years (range, 28-78 years). The proportions of small, medium and large aneurysms were $83.5,15.3$ and $1.2 \%$, respectively. Procedural complications occurred in 9 cases (10.5\%). The occlusion rate of the aneurysms was $98.8 \%$. The average follow-up period was $37.9( \pm 24.5)$ months. A total of $81.2 \%$
\end{abstract}

Correspondence to: Professor Ying Guo, Department of Neurosurgery, Third Affiliated Hospital of Sun Yat-Sen University, 600 Tianhe Road, Guangzhou, Guangdong 510630, P.R. China

E-mail: guoyingsysu@hotmail.com

Abbreviations: AComA, anterior communicating artery; BRAT, Barrow Ruptured Aneurysm Trial; CSF, cerebrospinal fluid; CTA, computed tomography angiography; EVD, extraventricular drainage; ICGA, indocyanine green angiography; ICH, intracerebral hemorrhage; ISAT, International Subarachnoid Aneurysm Trial; mRS, modified Rankin scale; SAH, subarachnoid hemorrhage; VP shunt, ventriculoperitoneal shunt; WFNS, World Federation of Neurological Surgeons; SOEK, supraorbital eyebrow keyhole approach

Key words: aneurysm, anterior communicating artery aneurysm, keyhole approach, supraorbital craniotomy of the patients with SAH had a good clinical prognosisat 1 year (modified Rankin scale score, $\leq 2$ ). In conclusion, for a skilled and experienced surgeon, SOEK was indicated to be a safe procedure for the treatment of ruptured AComA aneurysms; it provided sufficient intra-operative exposure and a high clipping rate.

\section{Introduction}

Anterior communicating artery (AComA) aneurysm is the most common type of anterior circulation aneurysm (1-3). It is symptomatic when rupture occurs, resulting in subarachnoid hemorrhage (SAH), which mostly accumulates in the suprasellar cistern, cerebral longitudinal fissure or cisterna lamia terminal is; at times, it may be associated with hematoma, particularly under the frontal lobe or in lateral ventricles (4).

In the field of neurosurgery, the minimally invasive keyhole approach has been gradually developed in the past 30 years. In the surgical treatment of anterior circulation aneurysms, with the deepening of the understanding of local microanatomy, continuous improvement of microsurgical techniques and the improvement of microsurgical instruments, the popularity of the keyhole approach for clipping aneurysms is increasing. Certain better alternatives to the pterional approach, including the supraorbital eyebrow approach (5), mini-pterional approach (6), mini-supraorbital approach (7) and lateral supraorbital approach (8) are also gradually used in anterior circulation aneurysm surgery. Skeptics of the supraorbital keyhole approach (SOEK) argue that it is difficult to approach ruptured aneurysms due to brain swelling (9-11). Furthermore, if an unexpected rupture occurs during the operation prior to proximal control of the feeding artery, it may not be possible for the surgeon to properly manage the bleeding. For this reason, SOEK surgery is mainly performed in patients with unruptured intracranial aneurysms and studies reporting on aneurysm rupture during SOEK are rare. Therefore, the feasibility of applying this type of keyhole surgery for ruptured intracranial aneurysm has not been determined.

The present study reported on the routine use of SOEK in the treatment of ruptured AComA aneurysms. 


\section{Materials and methods}

Study design, setting and participants. The present retrospective study was approved by the Institutional Review Board and ethics committee of the Third Affiliated Hospital of Sun Yat-Sen University (Guangzhou, China). Written informed consent was obtained from all patients or their custodians. Between September 2010 and October 2018, 543 patients with intracranial aneurysms were admitted to the Department of Neurosurgery of the Third Affiliated Hospital of Sun Yat-Sen University (Guangzhou, China). According to the patients' condition and choice, microsurgical clipping or interventional embolization were selected for treatment. Furthermore, if patients exhibited reduced consciousness then permission was obtained from their guardians. Among them, 85 patients with ruptured AComA aneurysm underwent microsurgical clipping via the SOEK approach. All 85 patients were diagnosed as having ruptured AComA aneurysm with $\mathrm{SAH}$ within $48 \mathrm{~h}$ after onset by CT angiography (CTA; 320-slice spiral CT, Aquilion ONE; Toshiba Medical Systems).

Variables and data sources. The clinical data collected included age, sex, Hunt and Hess scores (12), World Federation of Neurological surgeons (WNSF) scores (13), Fisher scores (14), aneurysm size, aneurysm location, aneurysm direction, operation time and complications. Intra-operative indocyanine green angiography (ICGA) was used to evaluate the success rate of clipping. The operation time was calculated from induction of anesthesia to completion of skin closure. Ischemic complications were confirmed by including new neurological deficits or changes in consciousness. Sudden neurological impairment during the peri-operative period, indicative of new infarction, was confirmed by CT scan/MRI.

\section{Surgical techniques}

Selection of surgical approach. Initially, the SOEK approach was selected regardless of the size, characteristics and complexity of the AComA aneurysm. After several years' experience of using the SOEK approach at our department, most ruptured AComA aneurysms were clipped via the SOEK approach except for cases associated with severe brain swelling and with a large amount of intracerebral hemorrhage (ICH). In those cases associated with severe brain swelling and with an ICH of $>100 \mathrm{cc}$, where decompression and evacuation of hemorrhage were required, the pterional approach was selected.

Operative timing and methods. All subjects underwent surgery within $48 \mathrm{~h}$ of the first SAH to reduce the risk of rebleeding. Of the 85 subjects, 21 underwent extraventricular drainage (EVD) prior to surgery. In general, the right surgical approach was used. In order to secure the parent artery in advance, the A1 dominant blood supply side was selected in the surgical approach when AComA complex variation was present.

Posture and anesthesia. All operations were performed under general anesthesia with tracheal intubation. The patient was placed in the supine position; the head was elevated to 15 degrees, then rotated $\sim 30$ degrees to the contralateral side, and finally tilted back to $\sim 20$ degrees. This caused the frontal lobe to retract downward due to gravity, thereby reducing brain retraction (Fig. 1).

Skin incision. Skin and subcutaneous fascia were incised along the lateral supraorbital foramen (to avoid injury to supraorbital nerve and blood vessel) along the superior orbital margin of the eyebrow, $4-5 \mathrm{~cm}$ in length. The upper forehead skin flap was pulled using a rubber band and the temporal muscle was pulled outward to expose the zygomatic process of the frontal bone. Similarly, the inferior, frontal and orbicularis oculi muscles were pushed down to the orbital margin and fixed with silk thread. The pericranium remained intact above the orbital margin. The fascial opening was opened downward to avoid the injury of the frontal branch of the facial nerve. The frontal is and orbital muscles were cut in a parallel fashion. The frontal is and orbicularis muscles were peeled from the bony insertion and gently pushed.

Craniotomy. A Burr hole was made behind the zygomatic process of the frontal bone, and the frontal bone was opened along the supraorbital margin from the outside to the inside. Next, a $3 \times 2.5 \mathrm{~cm}$ semilunar bone flap was fabricated (Fig. 2). The superior orbital margin and anterior skull base processes were drilled. If the frontal sinus was ruptured, the mucosa was removed, thoroughly cleaned with iodine solution and sealed with bone wax. Subsequently, the dura was opened in semilunar shape with its base facing towards the skull base. From this stage of the operation onwards, the microscope (Leica M530 OH6; Leica Microsystems GmbH) was used.

Intradural dissection. Upon opening of the lateral fissure, carotid cistern, optic chiasmatic cistern, basal cistern and endplate cistern, the cerebrospinal fluid (CSF) was fully released. At times, the subarachnoid space was filled with blood clots rather than CSF. In this case, it was difficult to release sufficient CSF to relax the brain tissue. At this time, CSF was drained in advance by inserting an EVD tube in the anterior horn of the contralateral ventricle. After opening the dura mater, slow release further provided CSF drainage to fully relax the brain tissue if required. It was possible to fully observe the end plate behind the carotid cistern and optic chiasma by placing an automatic retractor at the bottom of the frontal lobe and gradually exposing the frontal lobe to the optic nerve. At times, gyrus rectus resection may also help to fully expose the AComA complex. Dissection began from the internal carotid artery-A1 on the operative side; the distal end of the aneurysm-bearing artery A1 was dissected and the contralateral A1 was dissected. Subsequently, the adjacent A1, A2, AComA and the recurrent artery were gradually approached and separated from the aneurysmal neck. If necessary, temporary clipping of the ipsilateral and/or contralateral Alwas performed. The decision on whether or not to dissect the aneurysm may be made under consideration of the projection, size and adhesion of the aneurysm. Aneurysm clips of appropriate shape and size were selected and accurate clipping of the aneurysm was implemented. While clipping the aneurysm pointing downwards and forward through the SOEK approach, the exposure of the aneurysmal neck is obscured from the operative field, making the top of aneurysm dome more likely to rupture. In the case of adhesion between the dome of the aneurysm and 

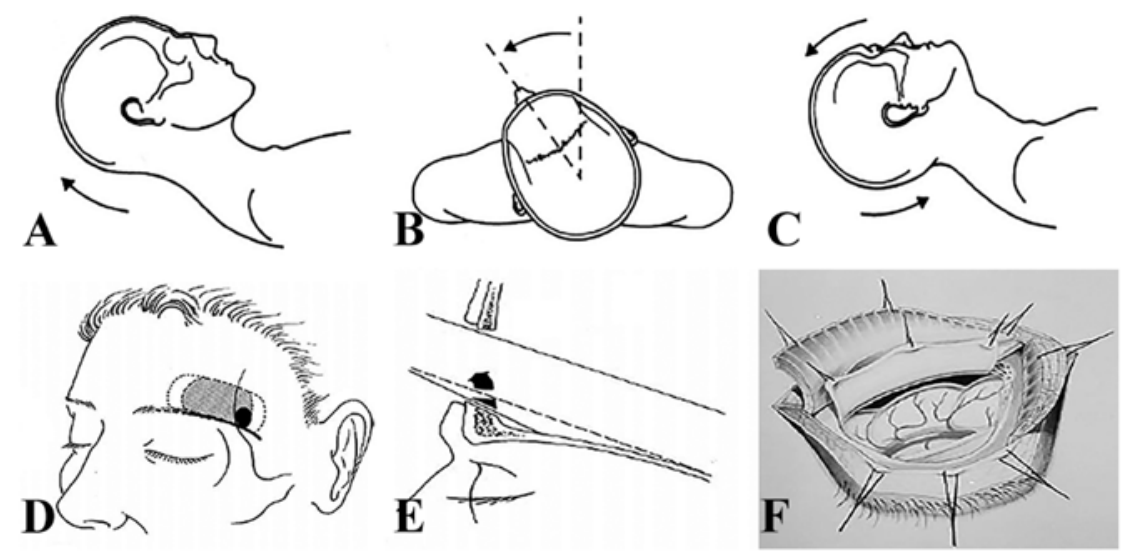

Figure 1. Schematic drawing of the supraorbital eyebrow keyhole approach. (A) The head was elevated to approximately $15^{\circ}$ to facilitate venous drainage. (B) The head was rotated to the contralateral side. (C) The maneuver of retroflexion supported gravity-associated self-retraction of the frontal lobe. (D) The skin incision in the eyebrow and the craniotomy are represented by dotted lines. (E) Drilling of the inner cortical layer of the orbital rim in to achieve optimal alignment with the orbital roof. (F) Preparation of the frontal and temporal muscle flaps caudally and laterally.
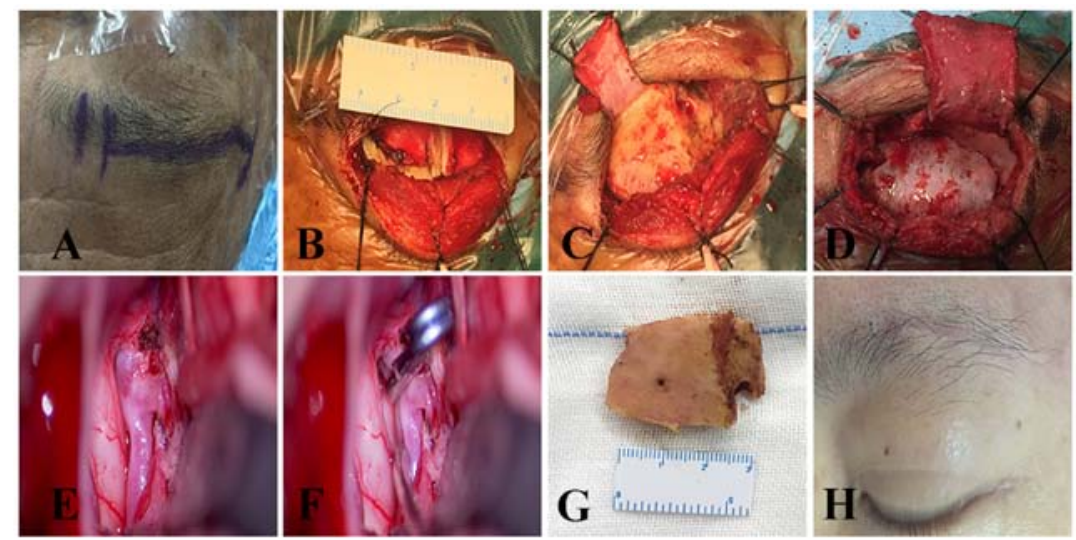

Figure 2. Intra-operativeimages of the procedure, supraorbital eyebrow keyhole approach. (A) The skin incision is planned along the eyebrow; (B) the muscular and skin flaps retracted with silk sutures. (C) A single burr hole is made below the superior temporal line and posterior to the keyhole. (D) A small supraorbital craniotomy is formed and the dura is opened with the base along the orbital rim. (E) Intra-operative exposure of aneurysm. (F) Clipping of anterior communicating artery aneurysm. (G) The bone flap produced after the supraorbital craniotomy (ruler units, cm). (H) Surgical incision 20 days after the operation.

the skull base caused by bleeding, inappropriate pulling of the frontal lobe may easily lead to rupture of the aneurysm during the operation. To avoid intra-operative rupture, the following points may be considered: i) Surgical approach from the side of the dominant blood supply, which is more conducive to controlling the aneurysm-bearing artery; ii) when exposure of the aneurysm neck is difficult, CSF should be released to obtain adequate space for clipping the AComA aneurysm. In the case of intra-operative rupture, the A1 segment may be temporarily occluded and the aneurysm neck may be rapidly separated followed by clipping of the aneurysm with an appropriate clip.

Closure. Prior to the closure of the dura, papaverine saline was used to fill the subdural space. Following careful hemostasis, the dura was sutured with silk thread in a waterproof manner. The frontal sinus, if open, was exteriorized, cleaned with iodine solution and sealed with bone wax. Bone flaps were fixed with a titanium plate and screws. The muscle was sutured in layers without a drainage catheter and the subcutaneous suture was made using prolene 4-0. All patients underwent surgery via the SOEK approach. None of these surgeries was assisted by endoscopy. All of the 85 patients underwent CTA examination the day after the operation.

Post-operative management. Conventional prophylactic intravenous drip of nimodipine was administered to prevent cerebral vasospasm. If necessary, adjuvants including dexamethasone and osmotic diuretics were used to control brain swelling. Routine lumbar puncture was performed to replace blood-infused cerebrospinal fluid. EVD was performed in patients with hydrocephalus. All patients were monitored at the post-operative intensive care unit.

Follow-up. All patients were followed up by neurosurgeons. Outpatient follow-up was the major method. Patients who were not able to visit the outpatient clinic were contacted by telephone to assess their neurological function. Clinical outcomes at 3,6 and 12 months post-operatively were assessed using a modified Rankin scale (mRS). A favorable outcome was defined as a $\mathrm{mRS}$ score of $\leq 2$. Furthermore, the risk factors of adverse prognosis ( $\mathrm{mRS}>3$ ) after 1 year were analyzed and the conventional CTA/digital subtraction angiography 
(DSA) imaging evaluation was performed at 3 months after the operation.

Statistical analysis. Continuous variables are expressed as the mean \pm standard deviation and categorical variables are expressed as n (\%). Differences were analyzed using Student's t-test for continuous variables and Fisher's exact test or $\chi^{2}$ test for categorical parameters. In the univariate logistic regression analysis [analyzed using SPSS 21.0 software (IBM Corp.)], statistical variables were determined to identify risk factors for poor clinical grade, including the odds ratio (ORs) and $95 \%$ CI. $\mathrm{P}<0.05$ was considered to indicate a statistically significant difference. SPSS software (version 21.0; IBM Corp.) was used for statistical analysis.

\section{Results}

General information. In the present study, 85 patients with ruptured AComA aneurysms were treated using the SOEK approach. The cohort comprised were 50 males and 35 females. The age of the patients ranged from 28 to 78 years (mean age, $52.69 \pm 9.94$ years; Table I).

Pre-operative evaluation. According to Fisher's grade of head CT prior to the operation, the cohort comprised 0 cases of grade I, 42 cases of grade II, 13 cases of grade III and 30 cases of grade IV. Furthermore, 17 patients had a Hunt and Hess grade of 1, 32 patients were grade 2, 25 patients were grade 3,9 patients were grade 4 and 2 patients were grade 5 . A total of 28 patients had a WFNS score I, 20 were WFNS score II, 12 were WFNS score III, 23 were WFNS score IV and 2 were WFNS score V. Table I summarizes the demographic characteristics of the 85 patients treated via the SOEK approach.

Aneurysmal number and size. All 85 patients were diagnosed with AComA aneurysm by CTA and 320-slice CT (Aquillion One; Toshiba). A total of 85 aneurysms were detected in the 85 patients with an average diameter of $5.07 \pm 2.36 \mathrm{~mm}$ (range, 2-11 $\mathrm{mm})$. Among them, the diameter of the small aneurysm ( $<7 \mathrm{~mm})$, medium aneurysm $(7-12 \mathrm{~mm})$ and large aneurysm (>12 mm) were 83.5, 15.3 and $1.2 \%$, respectively (Table I).

Aneurysmal directionality. According to the Yasargil typing method (15), the aneurysm pointed superiorly in 28 patients, inferiorly in 14 patients, anteriorly in 16 patients, posteriorly in 3 patients and toward multiple directions in 24 patients (Table I).

Association between aneurysmal directionality and pre-operative ICH. Pre-operative ICH was more prevalent in aneurysms pointing anteriorly than in the other aneurysms $(\mathrm{P}<0.014$; data not shown).

Association between Fisher grade and blood loss. Severe blood loss was more frequent in patients with poor Fisher grade (Grade III/IV; P<0.005).

AComA complex variation. Right-side dominant blood supply with congenital absence or hypoplasia of the left A1 was present in 16 patients, whereas the left-side dominant blood
Table I. Characteristics of patients with AComA aneurysm $(n=85)$.

\begin{tabular}{|c|c|}
\hline Characteristics & Value \\
\hline Sex (male/female) & $50 / 35$ \\
\hline Age (years) & $52.69 \pm 9.94(28-78)$ \\
\hline \multicolumn{2}{|l|}{ AComA complex variation } \\
\hline Right dominant blood supply & 16 \\
\hline Left dominant blood supply & 36 \\
\hline No marked variation & 33 \\
\hline \multicolumn{2}{|l|}{ Associated ICH grade } \\
\hline I (no ICH) & 63 \\
\hline II $(<50 \mathrm{cc})$ & 14 \\
\hline III $(50-100 \mathrm{cc})$ & 8 \\
\hline \multicolumn{2}{|c|}{ Pre-operative Hunt and Hess grade } \\
\hline 1 & $17(20.0)$ \\
\hline 2 & $32(37.6)$ \\
\hline 3 & $25(29.4)$ \\
\hline 4 & $9(10.6)$ \\
\hline 5 & $2(2.4)$ \\
\hline \multicolumn{2}{|c|}{ World Federation of Neurosurgical } \\
\hline \multicolumn{2}{|l|}{ Societies grade } \\
\hline I & $28(32.9)$ \\
\hline II & $20(23.5)$ \\
\hline III & $12(14.1)$ \\
\hline IV & $23(27.1)$ \\
\hline $\mathrm{V}$ & $2(2.4)$ \\
\hline \multicolumn{2}{|l|}{ Pre-operative Fisher grade on CT } \\
\hline 1 & $0(0.0)$ \\
\hline 2 & $42(49.4)$ \\
\hline 3 & $13(15.3)$ \\
\hline 4 & $30(35.3)$ \\
\hline \multicolumn{2}{|l|}{ Aneurysm size (mm) } \\
\hline Small $(<7)$ & $71(83.5)$ \\
\hline Medium (7-12) & $13(15.3)$ \\
\hline Large $(>12-<25)$ & $1(1.2)$ \\
\hline \multicolumn{2}{|l|}{ Aneurysmal directionality } \\
\hline Superior & 28 \\
\hline Inferior & 14 \\
\hline Anterior & 16 \\
\hline Posterior & 3 \\
\hline Complex & 24 \\
\hline
\end{tabular}

Values are expressed as the mean \pm standard deviation (range) or $\mathrm{n}(\%)$. AComA, anterior communicating artery; $\mathrm{ICH}$, intracerebral hemorrhage.

supply with congenital absence or hypoplasia of right A1 was present in 36 patients. Furthermore, 33 patients had no marked variation.

Surgical results. None of the patients undergoing surgery via the SOEK approach required conversion to a pterional 
microsurgical approach (Figs. 3 and 4). No aneurysm recurred after the operation. The average operation time (from induction of anesthesia to completion of skin closure) was $268.2 \pm 82.8 \mathrm{~min}$ (range, 60-360 $\mathrm{min}$ ). Pre-operative hydrocephalus was identified in 23 cases $(27.1 \%)$ and intracerebral hematoma in 31 cases (36.5\%). Pre-operative EVD was observed in 21 (24.7\%) cases. The incidence of frontal sinus opening occurred in 2 cases (2.4\%). However, despite the opening of the frontal sinus, no cerebrospinal fluid leakage occurred after proper treatment. Temporary clipping was performed in 25 patients (29.4\%). A total of 5 patients underwent partial excision of the gyrus rectus. Intra-operative rupture of the aneurysm during the operation occurred in 3 cases. The aneurysm-bearing artery was temporarily blocked and the aneurysm was then separated, followed by adequate clipping of the aneurysm neck. Delayed vasospasm occurred in 42 cases $(49.4 \%)$. A post-operative ventriculoperitoneal (VP) shunt was placed in 9 cases $(10.6 \%)$. No frontalis muscle palsy occurred in any of the patients.

Risk factors for early post-operative poor prognosis. A total of 85 patients were included in the univariate logistic regression analysis to investigate the risk factors associated with adverse clinical outcomes (mRS 3-6; Table II). Risk factors that were significant predicators of poor prognosis (mRS 3-6) included the Hunt \& Hess score, Fisher grade, WFNS score, ICH, pre-operative EVD, pre-operative hydrocephalus and VP shunt (Table III). These factors were determined using the $\chi^{2}$ test or Fisher's exact test $(\mathrm{P}=0.020, \mathrm{P}=0.003, \mathrm{P}=0.004, \mathrm{P}=0.001$, $\mathrm{P}=0.005, \mathrm{P}=0.002$ and $\mathrm{P}=0.006)$. Other risk factors, including age $(P=0.387)$, sex $(P=0.330)$, aneurysm size $(P=0.330)$, Anesthesia-to-skin time $(\mathrm{P}=0.065)$, vasospasm $(\mathrm{P}=0.889)$, gyrus rectus resection $(\mathrm{P}=0.436)$ and temporary clipping $(\mathrm{P}=0.777)$ during operation, had no significant influence on the prognosis (Table II).

Risk factors for poor long-term prognosis after surgery. Regarding poor-grade outcomes (mRS 3-6) at 12 months after surgery, univariate analysis suggested that the Hunt \& Hessgrade (OR=22.0, 95\% CI: 4.8-100.2, $\mathrm{P}=0.001)$, Fisher grade $(\mathrm{OR}=10.88,95 \% \mathrm{CI}: 2.292-51.74, \mathrm{P}=0.003)$, WFNS score $(\mathrm{OR}=6.0,95 \% \mathrm{CI}: 1.88-19.19, \mathrm{P}=0.003), \mathrm{ICH}(\mathrm{OR}=7.9$, 95\% CI: $2.41-25.97, \mathrm{P}=0.001)$, pre-operative $\mathrm{EVD}(\mathrm{OR}=6.1$, 95\% CI: $1.90-19.62, \mathrm{P}=0.002)$, pre-operative hydrocephalus $(\mathrm{OR}=10.45,95 \% \mathrm{CI}: 3.06-35.63, \mathrm{P}=0.001)$ and post-operative VP shunt $(\mathrm{OR}=4.26$, 95\% CI: 0.90-18.22, $\mathrm{P}=0.050$; Table III) were identified as influencing factors with statistical significance, but there was no statistical significance for operation time, vasospasm, gyrus rectus resection and temporary clipping (results not shown)

Occlusion rate of aneurysms and mortality. A complete occlusion rate of $98.8 \%(84 / 85)$ was achieved, as determined by intra-operative ICGA and follow-up imaging (CTA or DSA performed on the day after surgery for all cases). Aneurysm wrapping was performed in one case. Two patients with pre-operative Hunt \& Hess grade V died. At one year after treatment, $69(81.2 \%)$ patients attained a favorable outcome (mRS $\leq 2$; Table IV). Furthermore, $95.23 \%$ of the 42 patients with a Fisher grade of 2 had a favorable outcome (Table II).

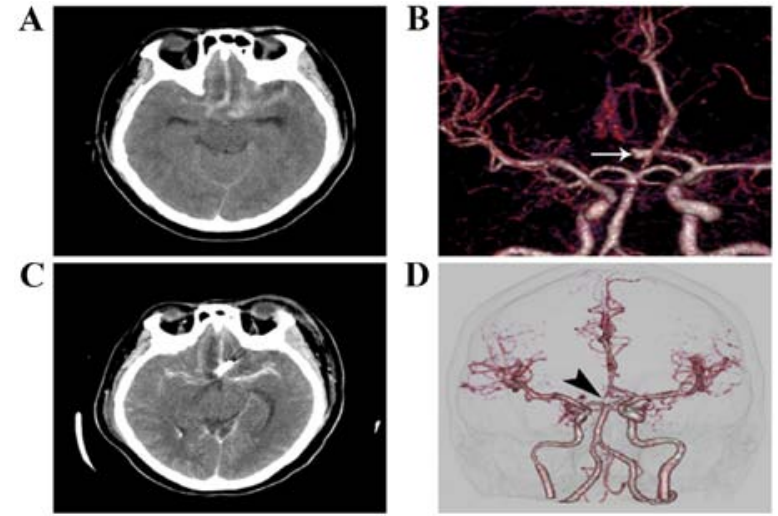

Figure 3. CT and CT angiography of 42-year-old female presenting with a headache and decreased consciousness disorder. (A) Pre-operative CT with subarachnoid hemorrhage. (B) Pre-operative CT angiography (white arrow indicates the aneurysm). (C) Postoperative CT with clipped aneurysm. (D) Post-operative CT angiography displaying complete clipping of the anterior communicating artery aneurysm via supraorbital eyebrow keyhole approach (arrowhead).
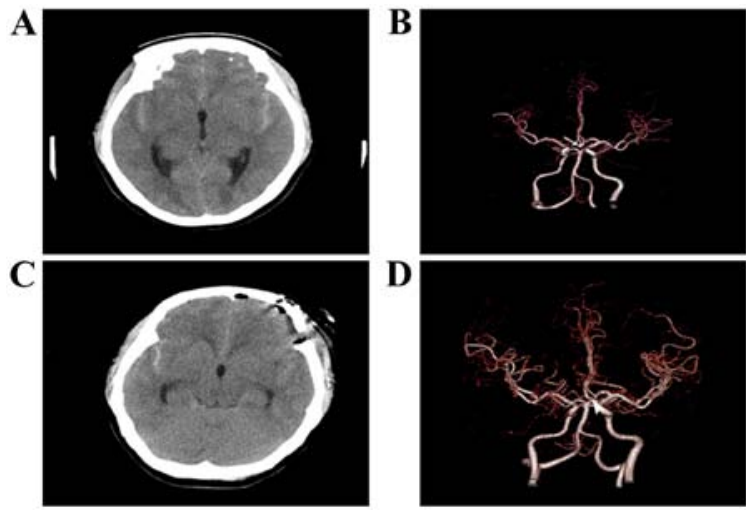

Figure 4. CT and CT angiography of a 29-year-old female presenting with a headache and vomiting. (A) Pre-operative CT with subarachnoid hemorrhage. (B) Pre-operative CT angiography (white arrow indicates the aneurysm). (C) Postoperative CT with clipped aneurysm. (D) Post-operative CT angiography displaying complete clipping of the anterior communicating artery aneurysm via supraorbital eyebrow keyhole approach (arrowhead)

Surgery-associated complications. A total of 9 patients $(10.5 \%)$ had surgery-associated complications. Procedural complications included 7 intracranial/wound infections $(8.23 \%)$ and 17 ischemic events. A total of 7 patients recovered completely within 6 months $(11.8 \%$; Table V). Early or late re-bleeding was not observed in any of the patients.

Post-operative follow-up. A total of 83 patients ( $n=85-2$ cases of mortality) were followed up for 6-88 months, with a mean follow-up time of $37.9 \pm 24.5$ months (Table V). There were no cases of wound infection, recurrent bleeding or neurological deterioration (data not shown).

\section{Discussion}

In recent years, endovascular therapy has increased in popularity among cerebrovascular surgeons. Therefore, in the surgical treatment of aneurysms, microclipping technology has gradually been replaced by endovascular therapy (16-20). 
Table II. Characteristics of patients with poor-grade outcomes (mRS score, 3-6).

\begin{tabular}{|c|c|c|c|c|}
\hline \multirow[b]{2}{*}{ Characteristics } & \multirow[b]{2}{*}{ Total $(n=85)$} & \multicolumn{2}{|c|}{ mRS score } & \multirow[b]{2}{*}{ P-value } \\
\hline & & Good grade $(n=69)$ & Poor grade $(n=16)$ & \\
\hline Age (years) & & & & 0.387 \\
\hline Mean \pm SD & $53 \pm 11.38$ & $52.51 \pm 9.13$ & $53.5 \pm 13.2$ & \\
\hline Median (range) & $50(29-78)$ & $52(29-78)$ & $51.5(28-76)$ & \\
\hline Sex & & & & 0.330 \\
\hline Male & $50(58.8)$ & $38(55.1)$ & $12(75.0)$ & \\
\hline Female & $35(41.2)$ & $31(44.9)$ & $4(25.0)$ & \\
\hline Hunt and Hess grade & & & & 0.020 \\
\hline $1-3$ & $74(87.1)$ & $66(95.7)$ & $8(50)$ & \\
\hline $4 / 5$ & $11(12.9)$ & $3(4.3)$ & $8(50)$ & \\
\hline Fisher grade & & & & 0.003 \\
\hline $1 / 2$ & $42(49.4)$ & $40(58.0)$ & $2(12.5)$ & \\
\hline $3 / 4$ & $43(50.6)$ & $29(42.0)$ & $14(87.5)$ & \\
\hline WFNS scale & & & & 0.004 \\
\hline I-III & $60(70.6)$ & $54(78.3)$ & $6(37.5)$ & \\
\hline $\mathrm{IV} / \mathrm{V}$ & $25(29.4)$ & $15(21.7)$ & $10(62.5)$ & \\
\hline Aneurysm size (mm) & & & & 0.169 \\
\hline Small $(<7)$ & $71(83.5)$ & $60(87.0)$ & $11(68.8)$ & \\
\hline Medium (7-12) & $13(15.3)$ & $8(11.6)$ & $5(31.3)$ & \\
\hline Large $(>12-<25)$ & $1(1.2)$ & $1(1.4)$ & $0(0.0)$ & \\
\hline Anesthesia-to-skin time (h) & & & & 0.065 \\
\hline Mean \pm SD & $4.5 \pm 1.38$ & $4.35 \pm 1.17$ & $5.13 \pm 1.97$ & \\
\hline Median (range) & $4.2(1-8.75)$ & $4.1(1-7.0)$ & $5.07(2-8.75)$ & \\
\hline Pre-operative EVD & & & & 0.005 \\
\hline No & $64(75.3)$ & 57 (82.6) & $7(43.8)$ & \\
\hline Yes & $21(24.7)$ & $12(17.4)$ & $9(56.3)$ & \\
\hline Vasospasm & & & & 0.089 \\
\hline No & $39(45.9)$ & 37 (53.6) & $2(12.5)$ & \\
\hline Yes & $46(54.1)$ & $32(46.4)$ & $14(87.5)$ & \\
\hline Hydrocephalus & & & & 0.002 \\
\hline No & $62(72.9)$ & 57 (82.6) & $5(31.3)$ & \\
\hline Yes & $23(27.1)$ & $12(17.4)$ & $11(68.8)$ & \\
\hline $\mathrm{ICH}$ & & & & 0.001 \\
\hline No & $63(74.1)$ & $57(82.6)$ & $6(37.5)$ & \\
\hline Yes & $22(25.9)$ & $12(17.4)$ & $10(62.5)$ & \\
\hline Gyrus rectus resection & & & & 0.436 \\
\hline No & $80(94.1)$ & $66(95.7)$ & $14(87.5)$ & \\
\hline Yes & $5(5.9)$ & $3(4.3)$ & $2(12.5)$ & \\
\hline Temporary clipping & & & & 0.777 \\
\hline No & $60(70.6)$ & $51(73.9)$ & $9(56.3)$ & \\
\hline Yes & $25(29.4)$ & $18(26.1)$ & $7(43.8)$ & \\
\hline VP shunt & & & & 0.006 \\
\hline No & $76(89.4)$ & $64(92.8)$ & $12(75.0)$ & \\
\hline Yes & $9(10.6)$ & $5(7.2)$ & $4(25.0)$ & \\
\hline Frontal sinus opening & & & & 0.204 \\
\hline No & $83(97.6)$ & 68 (98.6) & $15(93.8)$ & \\
\hline Yes & $2(2.4)$ & $1(1.4)$ & $1(6.3)$ & \\
\hline
\end{tabular}

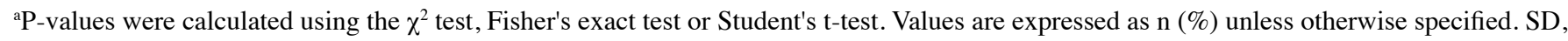
standard deviation; ICH, intracerebral hemorrhage; EVD, extraventricular drainage; mRS, modified Rankin scale; VP shunt, ventriculoperitoneal shunt; WFNS, World Federation of Neurosurgical Societies. 
Table III. Univariate analysis of risk factors associated with poor-grade outcomes (modified Rankin scale score, 3-6).

\begin{tabular}{lrr}
\hline Item & OR (95\% CI) & P-value \\
\hline Hunt and Hess grade (4/5 vs. 1-3) & $22.0(4.80-100.20)$ & 0.001 \\
Fisher grade (3/4 vs. 1/2) & $10.88(2.29-51.74)$ & 0.003 \\
WFNS scale (4/5 vs. 1-3) & $6.0(1.88-19.19)$ & 0.003 \\
ICH (yes vs. no) & $7.9(2.41-25.97)$ & 0.001 \\
Pre-operative EVD (yes vs. no) & $6.1(1.90-19.62)$ & 0.002 \\
Hydrocephalus (yes vs. no) & $10.45(3.06-35.63)$ & 0.001 \\
VP shunt (yes vs. no) & $4.26(0.90-18.22)$ & 0.050
\end{tabular}

EVD, extraventricular drainage; ICH, intracerebral hemorrhage; OR, odds ratio; VP shunt, ventriculoperitoneal shunt; WFNS, World Federation of Neurosurgical Societies.

Table IV. mRS scores of patients at 12 months post-operatively.

\begin{tabular}{lc}
\hline mRS score & Patients, $\mathrm{n}(\%)$ \\
\hline 0-No symptoms & $11(12.9)$ \\
1-No significant disability & $24(28.2)$ \\
2-Slight disability & $34(40.0)$ \\
3-Moderate disability & $3(3.5)$ \\
4-Moderately severe disability & $3(3.5)$ \\
5-Severe disability & $8(2.4)$ \\
6-Death (combined systemic disease) & $2(2.4)$ \\
Total/Loss to follow-up & $83 / 2$ \\
\hline
\end{tabular}

Values are expressed as $\mathrm{n}$ or $\mathrm{n}(\%)$. mRS, modified Rankin scale.

During a 10-year follow-up, both the residual and recurrence rates in the International Subarachnoid Aneurysm Trial (ISAT) (21) (34\%) and Barrow Ruptured Aneurysm Trial (BRAT) (22) (52\%) increased when compared with microsurgical clipping. In these two trials, $\sim 17 \%$ of patients required retreatment. As reported by Campi et al (21), the frequency of retreatment at the late stage of embolization increased nearly seven times as compared with the data of ISAT patients. Even with the use of novel equipment and technology, similar results have been obtained. For instance, Shapiro et al (23) reviewed 39 studies on the use of stent-assisted coils including 1,517 patients and indicated that the first complete occlusion rate of aneurysms was only $45 \%$. A recent study suggested that complete occlusion was achieved in only $56.1 \%$ of patients with wide-necked bifurcation aneurysms (24).

In addition to the recurrence rate, complications are also an important issue. In the ISAT, the rebleeding rate following interventional embolization of aneurysms was 2.5 times higher than that of microsurgical clipping (21). Moore et al (25) recently reported that the re-rupture rate of ruptured aneurysms after embolization was $7.7 \%$ and the residual or recurrence rate was $82 \%$. However, in the present study, no rebleeding was encountered.

The status of microsurgical clamping in the treatment of aneurysm has been gradually improved, particularly
Table V. Analysis of outcomes.

\begin{tabular}{lc}
\hline Outcome & Value \\
\hline Pre-operative hydrocephalus & $23(27.0)$ \\
Pre-operative EVD & $21(24.7)$ \\
Operating time (mean minutes) & $268.2(60-360)$ \\
Intra-operative blood loss (mean ml) & $165.26(50-600)$ \\
Frontal sinus opening & $2(2.4)$ \\
Temporary clipping & $25(29.4)$ \\
Gyrus rectus resection & $5(5.9)$ \\
Post-operative EVD & $9(10.6)$ \\
Post-operative VP shunt & $9(10.6)$ \\
Intraoperative aneurysm rerupture & $3(3.5)$ \\
Vasospasm (delayed) & $44(51.7)$ \\
Procedural complications & \\
Intracerebral hematoma & $7(8.2)$ \\
Ischemic events & $17(20.0)$ \\
Intracranial infection & $4(4.7)$ \\
Intracranial/wound infection & $3(3.5)$ \\
Duration of hospitalization (days) & $37.9 \pm 24.5$ \\
Mean follow-up (months) & $28.4(2-113)$ \\
Favorable outcome at follow-up & 81.2 \\
\hline
\end{tabular}

Values are expressed as the mean \pm standard deviation (range) or $n$ (\%). EVD, extraventricular drainage; VP shunt, ventriculoperitoneal shunt.

in the treatment of recurrent aneurysm after embolism. Daou et al (26) reported on 111 cases of recurrent aneurysm after embolism was surgically treated. AComA aneurysm accounted for $49.5 \%$. After clipping again, $97.3 \%$ of the aneurysms were completely occluded and $90 \%$ of the patients had good results at the final follow-up. While there is an absence of clear and complete treatment guidelines, microsurgical clipping appears to be a better choice for the treatment of recurrent aneurysms after embolization compared with coil embolization.

The major purpose of the keyhole approach is to minimize the trauma of craniotomy and obtain the best intracranial 
Table VI. Clinical outcomes of aneurysm surgery by supraorbital craniotomy.

\begin{tabular}{|c|c|c|c|c|c|c|c|}
\hline $\begin{array}{l}\text { First } \\
\text { author (year) }\end{array}$ & Patients (n) & $\begin{array}{c}\text { Unruptured } \\
\text { aneurysm, n }(\%)\end{array}$ & $\begin{array}{l}\text { Intra-operative } \\
\text { rupture }(\%)\end{array}$ & $\begin{array}{l}\text { Length of } \\
\text { stay (days) }\end{array}$ & $\begin{array}{c}\text { Good } \\
\text { outcome }(\%)\end{array}$ & $\begin{array}{l}\text { Peri-operative } \\
\text { complications }\end{array}$ & (Refs.) \\
\hline Paladino (1998) & 37 & NA & $3(8.1)$ & NA & 100 & Infection $(n=1)$ & (40) \\
\hline van Lindert (1998) & 139 & NA & $3(2.1)$ & NA & NA & None & (5) \\
\hline Chen (2009) & 88 & $0(0)$ & $23(26.1)$ & NA & 89 & Infection $(n=10)$ & (39) \\
\hline Tang (2013) & 76 & $6(7.9)$ & $8(10.5)$ & NA & 95 & $\begin{array}{l}\text { CSF leak }(n=3) \\
\text { Seizure }(n=4) \\
\text { Hyposmia }(n=6)\end{array}$ & (41) \\
\hline Chalouhi (2014) & 47 & $0(0)$ & $5(10.6)$ & NA & 77 & $\begin{array}{l}\text { Post-op hematoma }(n=1) \\
\text { Infection }(n=1) \\
\text { Infarction }(n=4)\end{array}$ & (42) \\
\hline Park (2018) & 188 & $0(0)$ & $2(1.0)$ & NA & 91.5 & $\begin{array}{l}\text { Infection }(n=3) \\
\text { Anosmia }(n=11) \\
\text { Infarction }(n=1)\end{array}$ & (38) \\
\hline Yu (2018) & 70 & $0(0)$ & $20(28.6)$ & 15.5 & 83.6 & $\begin{array}{l}\text { Infarction }(n=11) \\
\text { Infection }(n=7)\end{array}$ & (32) \\
\hline
\end{tabular}

CSF, cerebrospinal fluid; NA, information not available.

exposure without affecting the safety and effectiveness of surgical treatment. According to the experience of numerous neurosurgeons, the supraorbital keyhole approach has the following advantages: i) Small skin incision on the eyebrow ensures a good cosmetic effect; ii) reduction of brain tissue exposure; iii) short operation time and reduced use of general anesthetics; iv) rapid recovery after the operation; v) preservation of superficial temporal artery and frontal branch of the facial nerve; vi) lower incision complications; vii) shortened hospitalization time and reduced hospitalization costs $(27,28)$.

In the present study, the average operation time was 268.2 $\pm 1.38 \mathrm{~min}$ (range, 60-360 $\mathrm{min}$ ) and the average number of days of hospitalization was $28 \pm 19.05$ days (range, 2-113 days).

The posterior wall of frontal sinus may be injured during craniotomy via the SOEK approach. This defect may be the cause of CSF leakage and wound infection after the operation. To avoid frontal sinus wall injury during craniotomy, the lateral range of the frontal sinus should be assessed on the pre-operative CT. However, 2 patients had frontal sinus opening due to the prominent size of their sinus. If the frontal sinus is breached, the mucosa is removed, thoroughly cleaned with iodine solution and sealed with bone wax. Therefore, a wide frontal sinus is not an absolute contraindication for the keyhole approach.

Due to the 'keyhole effect', the SOEK approach provides sufficient exposure of the lateral fissure and is sufficient for arachnoid dissection and CSF drainage $(29,30)$. At times, in the case of a ruptured aneurysm, it is difficult to drain sufficient CSF, as the subarachnoid space is filled with blood clot instead of CSF.

In 2005, Paladino et al (31) compared keyhole craniotomy with pterional craniotomy. The keyhole group consisted of 482 patients with 565 aneurysms, while 146 patients with 167 aneurysms underwent pterional craniotomy. The mortality rate in the keyhole group was $0.83 \%$ (4 cases) and that in the standard craniotomy group was $2.05 \%$ (3 cases). In the present study, a good therapeutic effect was achieved in 69 of 85 patients $(81.2 \%)$ and 2 deaths occurred. The first case was a 68-year-old female with WFNS grade V and Fisher grade IV; aneurysm had a complex direction (multiple directions, the prominent direction was superior). On the pre-operative CT scans, this patient had an aneurysm of medium size $(8 \mathrm{~mm})$, which was associated with grade III bleeding $(50-100 \mathrm{ml})$. The patient also suffered severe bleeding during the operation and then developed a delayed ischemic defect due to perforator injury. The patient also contracted an intracranial infection. The second patient was a 67-year-old male with WFNS grade 4 and Fisher grade 4. The aneurysm featured anterior projection. On the pre-operative CT, a small aneurysm $(6.4 \mathrm{~mm})$ was identified, which was associated with grade II bleeding $(<50 \mathrm{ml})$. The operation time was $7.2 \mathrm{~h}$ and a delayed ischemic defect occurred. The two patients had pre-operative hydrocephalus and EVD was performed prior to surgery.

Yu et al (32) also performed a randomized controlled trial on keyhole craniotomy and pterional craniotomy for ruptured AComA aneurysm. Each group contained 70 cases. The operation time of the keyhole group was $141.9 \mathrm{~min}$, which was significantly lower than that of the pterional group (184.5 min). The incidence of surgical complications in the keyhole group was $10.5 \%$, which was lower than that in the pterional group (32.9\%). The long-term efficacy was comparable. In addition, the SOEK approach with only a single burr hole and small craniotomy may shorten the overall operation time and reduce craniotomy-associated complications, including CSF leakage, post-operative epidural hematoma and infection.

In 2014, Gupta et al (33) reported on the long-term prognosis of patients surviving ruptured intracranial aneurysm. Of the 494 patients with microsurgical clipping, 74 (15\%) had a 
poor prognosis at 1 year (mRS 3-6). In the BRAT, at 6 months of follow-up, 62 of the 170 patients $(36.5 \%)$ had poor outcomes (mRS 3-6) (22). In the present study, 16 patients (18.8\%) had poor outcome (mRS 3-6). The present results are similar to those of other studies (Table VI).

Accidental rupture of aneurysms is a major risk in all aneurysm surgeries. Van Lindert et al (5) reported an accidental rupture of an aneurysm during supraorbital keyhole surgery in 4 of 139 patients (3\%). In their experience report on a keyhole technique to clip aneurysms, Fischer et al (34) reported an intra-operative rupture rate of $7.7 \%$, which was associated with aneurysm size and amount of SAH.

The ISAT indicated that, under the condition that the majority of enrolled patients (88\%) were WFNS grade 1 or 2 , the rate of survivors with favorable outcomes ( $\mathrm{mRS}$ score $\leq 2)$ after 5 years was similar between surgical clipping (82\%) and coil embolization (83\%) (35). In the BRAT, $75 \%$ of patients treated by coil embolization and $72 \%$ of patients treated with clipping for anterior circulation aneurysms had an $\mathrm{mRS}$ score of $\leq 2$ at 1 year. After 6 years, this difference was still not significant $(22,36)$. In the present study, $81.2 \%$ of patients with ruptured aneurysm achieved good results; only $56.4 \%$ of patients in the present study were WFNS grade 1 and 2 . Furthermore, $47.1 \%$ of patients in this group had a Fisher grade 3 or 4 . As factors associated with adverse outcomes, the Hunt \& Hess score $(\mathrm{OR}=22.0,95 \% \mathrm{CI}: 4.8-100.2, \mathrm{P}=0.001)$, Fisher grade $(\mathrm{OR}=10.88,95 \% \mathrm{CI}: 2.292-51.74, \mathrm{P}=0.003), \mathrm{WFNS}$ score (OR 6.0, 95\%CI: 1.88-19.19, $\mathrm{P}=0.003), \mathrm{ICH}(\mathrm{OR}=7.9$, 95\% CI: 2.41-25.97, $\mathrm{P}=0.001)$, pre-operative EVD (OR=6.1, 95\%CI: $1.90-19.62, \mathrm{P}=0.002)$, hydrocephalus $(\mathrm{OR}=10.45,95 \%$ $\mathrm{CI}$ : $3.06-35.63, \mathrm{P}=0.001)$ and $\mathrm{VP}$ shunt $(\mathrm{OR}=4.26,95 \% \mathrm{CI}$ : 0.9-18.22, $\mathrm{P}=0.050$ ) were identified. Ogilvy and Carter (37) also reported similar results.

In the present study, surgical complications occurred in $10.5 \%$ of cases. Park et al (38) reported similar results. Their study described the experience of treating patients with ruptured anterior circulation aneurysm with SOEK. Chen et al (39) used the SOEK approach to treat ruptured anterior circulation aneurysm in a prospective, single-center study; the results were similar to those by Park et al (38), with a high rate of clipping. A favorable outcome was achieved in $88.6 \%$ of cases, no mortalities occurred and $10(11.4 \%)$ patients developed intracranial or wound infection.

However, there is no doubt that the SOEK method is a more challenging and technically demanding procedure with a steep learning curve, which limits its wide applicability to a certain extent. The SOEK method also has certain indications. In general, it is suitable for patients with a Hunt \& Hess grade of I-III, including conscious patients and patients without any severe intracranial pressure. Although it is also suitable for patients with Hunt \& Hess grade IV, its applicability depends on the state of brain cisterns, sulci and ventricles on CT imaging. However, it is generally not suitable for patients with a Hunt \& Hess grade with severe complications, including intracranial hypertension, brain hernia and requirement for enlargement of the bone window for decompression. In the SOEK approach, sufficient space may be obtained for clipping aneurysms by completely removing the skull base and releasing cerebrospinal fluid from the cistern. In addition, if necessary, pre-operative external ventricular drainage and/or resection of part of the gyrus rectus may be performed intra-operatively.

The major limitations of the present study include the small sample size, retrospective design, lack of randomization and outcome assessment performed by clinical surgeons. Finally, the present study reports on the clinical experience of specific surgical techniques and schemes at a single center, which limits the generalizability of the results. Furthermore, it may not be possible to extrapolate the present results to unruptured or posterior circulation aneurysms.

In conclusion, advancements in endovascular interventional techniques have reduced surgical clipping of aneurysms. Although the technology of endovascular interventional therapy is developing continuously, it does not provide an exact method for the treatment of residual aneurysms and retreatment remains necessary in a certain ratio of cases. With the advancement of minimally invasive microsurgery, small incision and bone window provide ideal exposure to clip AComA aneurysms. The present study indicated that the SOEK approach is an effective and ideal approach for clipping of AComA aneurysm; it has numerous advantages, including less trauma, a better therapeutic effect, fewer complications and lower cost when compared with coil embolization. However, due to the small operative space and difficult maneuvering of surgical instruments, a number of obstacles may be encountered during the operation. Therefore, it may be suggested that the individual treatment for patients with AComA should be selected based on pre-operative analysis.

\section{Acknowledgements}

Not applicable.

\section{Funding}

This work was supported by grants from the Science and Technology Program of Guangzhou, China (201604020080) and Guangdong Basic and Applied Basic Research Foundation(2018B0303110014)

\section{Availability of data and materials}

The datasets used and/or analyzed during the present study are available on reasonable request from the corresponding author.

\section{Authors' contributions}

RB and YG conceived and designed the current study. TCH, $\mathrm{CC}, \mathrm{HW}$ and XJN acquired the data. RB and CFL analyzed and interpreted the data, and drafted the manuscript. All authors read and approved the final version of the manuscript.

\section{Ethics approval and consent to participate}

Ethics approval was obtained from the Institutional Review Board and ethics committee of the Third Affiliated Hospital of Sun Yat-Sen University (Guangzhou, China) and all participants provided written informed consent prior to enrolment in the study. 


\section{Patient consent for publication}

Not applicable.

\section{Competing interests}

The authors declare that they have no competing interests.

\section{References}

1. Kassell NF, Torner JC, Haley EC Jr, Jane JA, Adams HP and Kongable GL: The international cooperative study on the timing of aneurysm surgery. Part 1: Overall management results. J Neurosurg 73: 18-36, 1990

2. Yasargil MG: Anterior cerebral and anterior communicating artery aneurysms. In Yasargil MG, (ed): Microneurosurgery, New York, Georg Thieme Verlag, Vol 2, pp180-185, 1984.

3. Lai LT, Gragnaniello C and Morgan MK: Outcomes for a case series of unruptured anterior communicating artery aneurysm surgery. J Clin Neurosci 20: 1688-1692, 2013.

4. Abla AA, Wilson DA, Williamson RW, Nakaji P, McDougall CG, Zabramski JM, Albuque FC and Spetzler RF: The relationship between ruptured aneurysm location, subarachnoid hemorrhage clot thickness, and incidence of radiographic or symptomatic vasospasm in patients enrolled in a prospective randomized controlled trial. J Neurosurg 120: 391-397, 2014.

5. van Lindert E, Perneczky A, Fries G and Pierangeli E: The supraorbital keyhole approach to supratentorial aneurysms: Concept and technique. Surg Neurol 49: 481-490, 1998.

6. Figueiredo EG, Deshmukh P, Nakaji P, Crusius MU, Crawford N, Spetzler RF and Preul MC: The minipterional craniotomy: Technical description and anatomic assessment. Neurosurgery 61 (5 Suppl 2): S256-S265, 2007.

7. Figueiredo EG, Deshmukh V, Nakaji P, Deshmukh P, Crusius MU, Crawford N, Spetzler RF and Preul MC: An anatomical evaluation of the mini-supraorbital approach and comparison with standard craniotomies. Neurosurgery 59 (4 Suppl 2): ONS212-ONS220, 2006.

8. Hernesniemi J, Ishii K, Niemelä M, Smrcka M, Kivipelto L, Fujiki $M$ and Shen H: Lateral supraorbital approach as an alternative to the classical pterional approach. Acta Neurochir Suppl 94: 17-21, 2005.

9. Nakajima H, Kamiyama $H$, Nakamura T, Takizawa $K$ and Ohata K: Direct surgical treatment of giant intracranial aneurysms on the anterior communicating artery or anterior cerebral artery. Neurol Med Chir (Tokyo) 53: 153-156, 2013.

10. Choi JH, Kang MJ and Huh JT: Influence of clinical and anatomic features on treatment decisions for anterior communicating artery aneurysms. J Korean Neurosurg Soc 50: 81-88, 2011.

11. Froelich S,Cebula H,Debry C and Boyer P: Anterior communicating artery aneurysm clipped via an endonasal approach: Technical note. Neurosurgery 68 (2 Suppl Operative): 310-316, 2011.

12. Hunt WE and Hess RM: Surgical risk as related to time of intervention in the repair of intracranial aneurysms. J Neurosurg 28 : $14-20,1968$

13. Report of World Federation of Neurological Surgeons Committee on a Universal Subarachnoid Hemorrhage Grading Scale. J Neurosurg: 68, 1988. Available from: https://thejns $\mathrm{org} / \mathrm{view} / \mathrm{journals} / \mathrm{j}$-neurosurg/68/6/article-jns.1988.68.6.0985. xml.xml.

14. Fisher CM, Kistler JP and Davis JM: Relation of cerebral vasospasm to subarachnoid hemorrhage visualized by computerized tomographic scanning. Neurosurgery 6: 1-9, 1980.

15. Yasargil MG: Microneurosurgery. Thieme Stratton Inc 2: 169-184, 1984

16. Lin N, Cahill KS, Frerichs KU, Friedlander RM and Claus EB: Treatment of ruptured and unruptured cerebral aneurysms in the USA: A paradigm shift. J Neurointerv Surg 4: 182-189, 2012.

17. Huang MC, Baaj AA, Downes K, Youssef AS, Sauvageau E, van Loveren HR and Agazzi S: Paradoxical trends in the management of unruptured cerebral aneurysms in the United States: Analysis of nationwide database over a 10 -year period. Stroke 42: 1730-1735, 2011.

18. Kozba-Gosztyla M, Czapiga B and Jarmundowicz W: Aneurismal subarachnoid hemorrhage: Who remains for surgical treatment in the post-ISAT era? Arch Med Sci 11: 536-543, 2015.
19. Koh KM, Ng Z, Low SY, Chua HZ, Chou N, Low SW and Yeo TT: Management of ruptured intracranial aneurysms in the post-ISAT era: Outcome of surgical clipping versus endovascular coiling in a Singapore tertiary institution. Singapore Med J 54: 332-338, 2013.

20. Niemela M, Koivisto T, Kivipelto L, Ishii K, Rinne J, Ronkainen A, Kivisaari R, Shen H, Karatas A, Lehecka M, et al: Microsurgical clipping of cerebral aneurysms after the ISAT Study. Acta Neurochir Suppl 94: 3-6, 2005.

21. Campi A, Ramzi N, Molyneux AJ, Summers PE, Kerr RS, Sneade M, Yarnold JA, Rischmiller J and Byrne JV: Retreatment of ruptured cerebral aneurysms in patients randomized by coiling or clipping in the International Subarachnoid Aneurysm Trial (ISAT). Stroke 38: 1538-1544, 2007.

22. Spetzler RF, McDougall CG, Zabramski JM, Albuquerque FC, Hills NK, Russin JJ, Partovi S, Nakaji P and Wallace RC: The Barrow ruptured aneurysm trial: 6-year results. J Neurosurg 123: 609-617, 2015.

23. Shapiro M, Becske T, Sahlein D, Babb J and Nelson PK: Stent-supported aneurysm coiling: A literature survey of treatment and follow-up. AJNR Am J Neuroradiol 33: 159-163, 2012.

24. Pierot L, Costalat V, Moret J, Szikora I, Klisch J, Herbreteau D, Holtmannspötter M, Weber W, Januel AC, Liebig T, et al: Safety and efficacy of aneurysm treatment with WEB: Results of the WEBCAST study. J Neurosurg 124: 1250-1256, 2016.

25. Moore N, Lang M and Bain M: 603. Rehemorrhage and recurrence rates of small ACOM aneurysms post embolization. Oral Presentations 2016 AANS Annual Scientific Meeting Chicago, IL. J Neurosurg 124: A1152, 2016.

26. Daou B, Chalouhi N, Starke RM, Barros G, Ya'qoub L, Do J, Tjoumakaris S, Rosenwasser RH and Jabbour P: Clipping of previously coiled cerebral aneurysms: Efficacy, safety, and predictors in a cohort of 111 patients. J Neurosurg 125: 1337-1343, 2016.

27. Reisch R, Perneczky A and Filippi R: Surgical technique of the supraorbital key-hole craniotomy. Surg Neurol 59: 223-227, 2003.

28. Yasargil MG, Reichman MV and Kubik S: Preservation of the frontotemporal branch of the facial nerve using the interfascial temporalis flap for pterional craniotomy. Technical article. J Neurosurg 67: 463-466, 1987.

29. Cheng CM, Noguchi A, Dogan A, Anderson GJ, Hsu FP, McMenomey SO and Delashaw JB Jr: Quantitative verification of the keyhole concept: A comparison of area of exposure in the parasellar region via supraorbital keyhole, frontotemporal pterional, and supraorbital approaches. J Neurosurg 118: 264-269, 2013.

30. Yagmurlu K, Safavi-Abbasi S, Belykh E, Kalani MYS, Nakaji P, Rhoton AL Jr, Spetzler RF and Preul MC: Quantitative anatomical analysis and clinical experience with mini-pterional and mini-orbitozygomatic approaches for intracranial aneurysm surgery. J Neurosurg 127: 646-659, 2017.

31. Paladino J, Mrak G, Miklić P, Jednacak H and Mihaljević D: The keyhole concept in aneurysm surgery-a comparative study: Keyhole versus standard craniotomy. Minim Invasive Neurosurg 48: 251-258, 2005

32. Yu LB, Huang Z, Ren ZG, Shao JS, Zhang Y, Wang R and Zhang D: Supraorbital keyhole versus pterional craniotomies for ruptured anterior communicating artery aneurysms: A propensity score-matched analysis. Neurosurgical Rev: Nov 10, 2018 doi: 10.1007/s10143-018-1053-y (Epub ahead of print).

33. Gupta SK, Chhabra R, Mohindra S, Sharma A, Mathuriya SN, Pathak A, Tewari MK, Mukherji KK, Singla N, Salunke P, et al: Long-term outcome in surviving patients after clipping of intracranial aneurysms. World Neurosurg 81: 316-321, 2014.

34. Fischer G, Stadie A,Reisch R,Hopf NJ,Fries G, Böcher-SchwarzH, van Lindert E, Ungersböck K, Knosp E, Oertel J and Perneczky A: The keyhole concept in aneurysm surgery: Results of the past 20 years. Neurosurgery 68 (1 Suppl Operative): 45-51, 2011.

35. Molyneux AJ, Kerr RS, Birks J, Ramzi N, Yarnold J, Sneade M and Rischmiller J; ISAT Collaborators: Risk of recurrent subarachnoid haemorrhage, death, or dependence and standardized mortality ratios after clipping or coiling of an intracranial aneurysm in the International Subarachnoid Aneurysm Trial (ISAT): Long-term follow-up. Lancet Neurol 8: 427-433, 2009.

36. Spetzler RF, McDougall CG, Albuquerque FC, Zabramski JM, Hills NK, Partovi S, Nakaji P and Wallace RC: The barrow ruptured aneurysm trial: 3-year results. J Neurosurg 119: 146-157, 2013.

37. Ogilvy CS and Carter BS: A proposed comprehensive grading system to predict outcome for surgical management of intracranial aneurysms. Neurosurgery 42: 959-970, 1998. 
38. Park JS, Kim H, Baik MW and Park IS: Risk factor analysis for poor outcomes in supraorbital keyhole aneurysm clipping for ruptured anterior circulation aneurysms. World Neurosurgery 111: e386-e394, 2018.

39. Chen L, Tian X, Zhang J, Huang Y, Chen E and Lan Q: Is eyebrow approach suitable for ruptured anterior circulation aneurysms on early stage: A prospective study at a single institute. Acta Neurochir (Wien) 151: 781-784, 2009.

40. Paladino J, Pirker N, Štimac D and Stern-Padovan R: Eyebrow keyhole approach in vascular neurosurgery. Minim Invasive Neurosurg 41: 200-203, 1998.

41. Tang C, Sun J, Xue H, Yu Y and Xu F: Supraorbital keyhole approach for anterior circulation aneurysms. Turk Neurosurg 23 : 434-438, 2013.
42. Chalouhi N, Thakkar V, Tjoumakaris S, Fernando Gonzalez L, Hasan D, Rosenwasser R, Singhal S and Jabbour PM: Microsurgical clipping of large and giant cerebral aneurysms: A single-center contemporary experience. J Clin Neurosci 21: 1424-1427, 2014.

This work is licensed under a Creative Commons Attribution-NonCommercial-NoDerivatives 4.0 International (CC BY-NC-ND 4.0) License. 